\title{
The effect of differential feeding histories on the distribution of home cage activity'
}

RICHARD K. LORE AND N. JANE GERSHAW

DOUGLASS COLLEGE, RUTGERS- THE STATE UNIVERSITY

The temporal distribution of home cage activity following food deprivation was influenced by both prior deprivation experience and an animal's previously acquired food getting habits.

A number of investigators have questioned the traditional assumption that changes in general activity reflect the strength of a drive or need state and have argued that activity level following food deprivations (FD) is largely determined by associative factors (reviewed by Baumeister, Hawkins, \& Cromwell, 1964). The latter position implies that activity level is dependent upon an animal's previous deprivation experience. Relevant to this, numerous studies have found abrupt increases in activity just prior to the daily feeding period following a period of cyclic deprivation (Bolles, 1963; Bolles \& Stokes, 1965; Finger, Reid \& Weasner, 1960; Reid \& Finger, 1955). This anticipatory effect appears to be mediated by external cues that have been regularly associated with the onset of feeding and, therefore, are not controlled by need stimuli per se.

A second potentially important associative factor which may influence an animal's response to FD involves the amount of energy expenditure that has accompanied past feeding experiences. Thus, the activity pattern of an animal whose feeding history has required large amounts of activity (e.g., exploring, social stimulation, food competition) should be different from that of an animal whose food-getting habits have required only a minimal expenditure of energy. In the present study an attempt was made to answer this question by experimentally controlling the conditions under which $\mathrm{S}$ was fed.

\section{Method}

Subjects. The Ss were 36 male rats of the Wistar strain obtained from Edgewood Breeders, Colonia, New Jersey. All Ss were weaned and delivered on day 25.

Free-feeding group. Twelve Ss were housed continuously from day 25-30 in a large free environment cage ( $48 \times 26 \times 10$ in.) constructed of hardward cloth. On day 31 , Ss were individually housed in standard cages $(7 \times 10 \times 7$ in.), and maintained on a $21 \mathrm{hr}$. FD schedule for the next 30-33 days. The daily $3 \mathrm{hr}$. feeding period occured in the free environment cage and began with the onset of the dark portion of the diurnal cycle. Purina mouse breeder pellets were scattered freely over the floor of the large feeding cage. Under these conditions social stimulation coupled with ample room and scattered food elicited high rates of activity in these Ss which were consistently associated with feeding. Observations made during feeding revealed that play activity inhibited eating during the first 15-20 min. of the feeding sessions and that activity was maintained at a fairly high rate throughout the session.

Restricted feeding group. Twelve Ss were housed continuously from day 25-30 in individual cages which were reduced in size $(7 \times 5 \times 7$ in.) by placing a wooden partition within the cage. Beginning on day 31 and lasting until day 60-63, these Ss were housed individually in standard cages and allowed to feed alone in the small cages for $3 \mathrm{hr}$. per day from pellets scattered on the floor. The feeding period of these animals also began with the onset of the dark portion of the diurnal cycle.

Control group. Twelve animals were individually housed in standard cages from day 25 to day 60-63 with food available ad lib.

Water was continuously available for all Ss throughout the study. The experiment was conducted in a small room that was maintained at a relatively constant $75^{\circ} \mathrm{F}$.

Home cage activity. Three ultrasonic motion detectors (Peacock \& Williams, 1962) were mounted on a mobile cart so that each unit's two transducers could be readily switched from cage to cage. The transducers were vertically mounted in a small wooden block glued to the feeding bin of each cage so that they bisected the cage's midline. The output of each motion detector was fed into a transitorized logic circuit which gated the clock pulses of two cascaded decade interval timers (Hunter Klockometer, model 120A). Relative calibration was accomplished by inserting a slowly oscillating plywood target into an empty test cage. Each unit was adjusted to give a reading of $45 \pm 1.0$ sec. during a standard $3 \mathrm{~min}$. test period. Under these conditions the repeat accuracy of these devices is extremely high. Further work indicated that the units were equally sensitive to movement occuring in any cage quadrant and gave an accurate measure of the relative time spent by each animal in any kind of physical activity ranging from grooming to locomotion.

Procedure. The initiation of each treatment condition was separated by two weeks in order to reduce the time spent in the testing phase of the experiment. Beginning on day $60-63$, three animals were food deprived in their home cages for a single $24 \mathrm{hr}$. period. For all Ss, this period began $3 \mathrm{hr}$. after the onset of the dark portion of the diurnal cycle (i.e. at the termination of the last feeding period of the restricted-feeding and free-feeding groups). Activity readings were taken after 
Table 1.

Home cage activity of the three treatment groups in seconds

\begin{tabular}{lcclc} 
& & $\begin{array}{l}18 \mathrm{hr} \\
\text { baseline } \\
\text { period }\end{array}$ & $\begin{array}{l}3 \mathrm{hr} . \\
\text { prefeeding } \\
\text { period }\end{array}$ & $\begin{array}{l}3 \mathrm{hr} . \\
\text { feeding } \\
\text { period }\end{array}$ \\
\cline { 3 - 5 } Group & $\mathrm{N}$ & Mean \& (SD) & Mean \& (SD) & Mean \& (SD) \\
\hline Control & 11 & $\begin{array}{c}1,569.82 \\
(271.54)\end{array}$ & $\begin{array}{l}168.64 \\
(97.35)\end{array}$ & $\begin{array}{c}272.27 \\
(108.47)\end{array}$ \\
$\begin{array}{l}\text { Restricted } \\
\text { Feeding }\end{array}$ & 9 & $\begin{array}{c}1,367.50 \\
(230.44)\end{array}$ & $\begin{array}{l}287.12 \\
(111.68)\end{array}$ & $\begin{array}{c}402.88 \\
(174.48)\end{array}$ \\
$\begin{array}{l}\text { Free } \\
\text { Feeding }\end{array}$ & 12 & $\begin{array}{c}1,014.83 \\
(204.12)\end{array}$ & $\begin{array}{l}277.42 \\
(74.09)\end{array}$ & $\begin{array}{c}425.50 \\
(103.98)\end{array}$ \\
\hline
\end{tabular}

the first $18 \mathrm{hr}$. (baseline period), after the next $3 \mathrm{hr}$. (prefeeding period), and after the last $3 \mathrm{hr}$. (feeding period).

\section{Resulis and Discussion}

Three Ss in the restricted-feeding group and one control $\mathrm{S}$ died before completion of the treatments, hence the results are based upon a total of $32 \mathrm{Ss}$. Table 1 summarizes the home cage activity data of the animals. The group differences in baseline period activity are significant $(F=10.74, \mathrm{df}=2 / 29, \mathrm{p}<.001)$ and a multiple mean comparison test (Kramer, 1956) revealed that the baseline activity of the free-feeding animals was significantly lower than that of the other two groups $(p<.05)$.

A mixed model analysis of variance of the prefeeding-feeding periods data indicated that both deprived groups were more active than the control Ss during this time period ( $F=6.20$, of $=2 / 29, p<.01$ ). All three groups were more active during the feeding period $(\mathrm{F}=40.80, \mathrm{df}=2 / 29, \mathrm{p}<.001)$ and the nonsignificant period by treatments interaction $(F=.58)$ indicated that the increase was uniform for all groups. Finally, group differences in activity over the entire $24 \mathrm{hr}$. period were not significant $(F=2.07, d f=2 / 29, p>.05)$.

The free-feeding animals were less active during the baseline period but exhibited a sharper increase in activity during the prefeeding-feeding period. Over the entire $24 \mathrm{hr}$. there were no group differences in activ- ity level. Hence, the primary effect of the differential feeding conditions involved a modification of the temporal distribution of activity following food deprivation. An animal whose food seeking behavior is conducted in a setting that consistently elicits high rates of activity appears to compensate for the increase by eliminating other physical activities in order to maintain energy expenditure at a relatively constant level.

In addition, the increased activity of both groups of cyclically-deprived animals during the $6 \mathrm{hr}$. prefeeding-feeding period indicates that the anticipatory effect observed in activity wheels is also present in the home cage environment. Using an observational technique, Bolles (1965) also found anticipatory increases in the home cage activity of animals fed diurnally. Thus the effect is not dependent upon the use of a measuring device that either measures a specific response (i.e., running) that can be reinforced by feeding or that generates a great deal of response produced feedback. Again, the results suggest that the total behavioral output remains unchanged; cyclic deprivation effects the temporal distribution of activity, not the total incident of activity.

\section{References}

Bolles, R. C. Effect of food deprivation upon the rat's behavior in its home cage. J. comp. physiol. Psychol., 1963, 56, 456-460.

Bolles, R. C., \& Stokes, L. W. Rat's anticipation of diurnal and a-diurnal feeding. J. comp. physiol. Psychol., 1965, 60, 290-294.

Baumeister, A., Hawkins, W. F., \& Cromwell, R. L. Need states and activity level. Psychol. Bull., 1964, 61, 438-453.

Finger, F. W., Reid, L. S., \& Weasner, M. H. Activity changes as a function of reinforcement under low drive. J. comp. physiol. Psychol., 1960, 53, 385-387.

Hall, J. F. The influence of learning in activity wheel behavior. J. genet. Psychol., 1958, 92, 121-125.

Kramer, C. Y. Extension of multiple range tests to group means with unequal numbers of replications. Biometrics, 1956, 12, 307-310.

Peacock, L. J., \& Williams, M. An ultrasonic device for recording activity. Amer. J. Psychol., 1962, 75, 648-652.

Reid, L. S., \& Finger, F. W. The rat's adjustment to 23 hour fooddeprivation cycles. J. comp. physiol. Psychol., 1955, 48, 110113.

Nole

1. Supported by a grant from the Rutgers Research Council. 